\title{
Factors Affecting the Function of the Mitochondrial Membrane Permeability Transition Pore and Their Role in Evaluation of Calcium Retention Capacity Values
}

\author{
Zdeněk DRAHOTA ${ }^{1,2}$, René ENDLICHER ${ }^{1,3}$, Otto KUČERA $^{1}$, David RYCHTRMOC ${ }^{1}$, \\ Zuzana ČERVINKOVÁ ${ }^{1}$
}

${ }^{1}$ Department of Physiology, Faculty of Medicine in Hradec Kralove, Charles University, Czech Republic, ${ }^{2}$ Laboratory of Bioenergetics, Institute of Physiology of the Czech Academy of Sciences, Prague, Czech Republic, ${ }^{3}$ Department of Anatomy, Faculty of Medicine in Hradec Kralove, Charles University, Hradec Kralove, Czech Republic

Received November 22, 2019

Accepted February 25, 2020

Epub Ahead of Print May 29, 2020

\begin{abstract}
Summary
Values of the calcium retention capacity (CRC) of rat liver mitochondria are highly dependent on the experimental conditions used. When increasing amounts of added calcium chloride are used (1.25-10 nmol), the values of the CRC increase 3 -fold. When calcium is added in $75 \mathrm{~s}$ intervals, the CRC values increase by $30 \%$ compared with $150 \mathrm{~s}$ interval additions. CRC values are not dependent on the calcium/protein ratio in the measured sample in our experimental design. We also show that a more detailed evaluation of the fluorescence curves can provide new information about mitochondrial permeability transition pore opening after calcium is added.
\end{abstract}

\section{Key words}

Liver mitochondria - Calcium retention capacity • Mitochondrial permeability transition pore

\section{Corresponding author}

Z. Červinková, Department of Physiology, Faculty of Medicine in Hradec Králové, Charles University, Šimkova 870, 50003 Hradec Králové, Czech Republic. E-mail: wolff@lfhk.cuni.cz

\section{Introduction}

The mitochondrial permeability transition pore (MPTP) activated by calcium ions plays an important role in the development of necrotic and apoptotic processes (Smith et al. 2012). This pore was discovered sixty-seven years ago (Raaflaub 1953) as a nonspecific pore in the inner mitochondrial membrane that enables penetration of molecules with molecular weights less than $1.5 \mathrm{kD}$. Its opening results in dissipation of the mitochondrial membrane potential and inhibition of ATP generation. Many studies have confirmed the existence of MPTP and described its properties and functions, e.g. its activation by calcium, phosphate, fatty acids and prooxidants; its inhibition by $\mathrm{Mg}$ ions and $\mathrm{ADP}$; and the role of cyclophilin D and cyclosporine in calcium-dependent pore opening (Halestrap et al. 1997, Carafoli et al. 2001, Halestrap 2009). However, the molecular structure of the pore has not yet been elucidated. Many mitochondrial proteins have been proposed as components of its structure (Halestrap 2009, Bernardi 2013, Alavian et al. 2014), but none have been confirmed by molecular genetic studies (He et al. 2017).

All basic information about MPTP function, regulation, tissue-specificity (Panov et al. 2007, Endlicher et al. 2009), age-specificity (Drahota et al. 2012b) and sex-specificity (Milerová et al. 2016) and its participation in the pathogenesis of many diseases was obtained through the assessments with spectrophotometric measurements of mitochondrial swelling induced by calcium ions. We have improved this graphical method using derivation of the swelling curves. After swelling curve derivation, two further parameters, in addition to the extent of swelling, can be acquired in

PHYSIOLOGICAL RESEARCH • ISSN 1802-9973 (online) 
a numeric form: the maximum swelling rate and the time at which the maximum swelling rate was reached after calcium addition (Drahota et al. 2012a).

More recently, a new approach based on a different principle has been used to evaluate the function and regulation of the MPTP in various mitochondrial preparations. The rationale of the method is based on the determination of the calcium retention capacity (CRC) value using the membrane impermeable fluorophore Calcium Green-5N (Ichas et al. 1997, Fontaine et al. 1998a). Calcium retention capacity indicates the number of calcium ions that must accumulate in mitochondria to induce pore opening. By this procedure, all information obtained from swelling measurements was confirmed. In addition, new data about pore regulation and function in various tissues and various pathological processes were obtained. However, this method of measuring CRC values has not yet been well standardized; therefore, the data obtained by various laboratories cannot be easily compared. According to our measurements, the CRC values are highly dependent on the composition of the incubation medium (Endlicher et al. 2019). In this communication, we describe that the $\mathrm{CRC}$ values are also dependent on the experimental protocol used. The main factors that affect the detection of CRC values are the calcium amount used for titration, and time interval between calcium additions. We also demonstrate that additional information about the process of pore opening during titration with calcium may be obtained from the resultant fluorometric curves.

\section{Methods}

\section{Chemicals}

All chemicals, unless otherwise stated, were of analytical grade and obtained from Sigma-Aldrich (Darmstadt, Germany). Calcium Green-5N was obtained from Thermo Fisher Scientific Inc. (Waltham, MA, USA).

\section{Animals}

Male Wistar rats $(215 \pm 15 \mathrm{~g})$ were obtained from Velaz (Lysá nad Labem, Czech Republic). The rats were housed at $23 \pm 1{ }^{\circ} \mathrm{C}$ and $55 \pm 10 \%$ humidity, with air exchange 12-14 times/h and a $12 \mathrm{~h}$ light-dark cycle period. The animals had free access to a standard laboratory diet (ST-1, Velaz, Czech Republic) and tap water. All animals received care according to the guidelines set by the Animal-Welfare Body of Charles
University, Czech Republic, and the EU Directive 2010/63/EU for animal experiments. Protocols complied with ARRIVE guidelines. The animals were sacrificed during deep inhalation of general inhalation anaesthesia by exsanguination from the aortic bifurcation. The livers were removed, washed in the cold isolation medium described below, and cut into small pieces.

\section{Isolation of mitochondria}

Liver mitochondria were isolated as previously described (Bustamante et al. 1977). The washed and cut $3 \mathrm{~g}$ liver tissue was homogenized at $0{ }^{\circ} \mathrm{C}$ by a Teflonglass homogenizer in an isolation medium containing $220 \mathrm{mM}$ D-mannitol, $70 \mathrm{mM}$ sucrose, $2 \mathrm{mM}$ HEPES, $0.2 \mathrm{mM}$ EGTA, and $0.5 \mathrm{~g}$ of fatty acid-free bovine serum albumin (BSA) per liter at $\mathrm{pH} 7.2$. The $10 \%$ homogenate was centrifuged for $4 \mathrm{~min}$ at $830 \mathrm{xg}$, and the resulting supernatant was centrifuged for $15 \mathrm{~min}$ at $5200 \mathrm{x} \mathrm{g}$. The mitochondrial sediment was washed during two $10 \mathrm{~min}$ centrifugations (at 11200 and at $13000 \mathrm{xg}$ ) in isolation medium lacking EGTA and resuspended in the same medium to a final volume of $3 \mathrm{ml}$. Isolated mitochondria were stored at $0{ }^{\circ} \mathrm{C}$. The calcium retention capacity was measured immediately after isolation

\section{Determination of mitochondrial proteins}

The mitochondrial protein concentration was determined using the Bradford method with bovine serum albumin as a standard (Bradford 1976).

\section{Measurement of calcium retention capacity}

The mitochondrial retention capacity for calcium was evaluated using the membrane-impermeable fluorescent probe Calcium Green-5N on an AMINCOBowman Series 2 spectrofluorometer (Thermo Electron Corporation) at an excitation wavelength of $506 \mathrm{~nm}$ and emission wavelength of $592 \mathrm{~nm}$. Measurements were performed at room temperature. A total of $1 \mathrm{ml}$ of medium (125 mM sucrose, $65 \mathrm{mM} \mathrm{KCl}$, and $10 \mathrm{mM}$ HEPES at $\mathrm{pH}$ 7.2), $1 \mu \mathrm{M}$ Calcium Green-5N, $10 \mathrm{mM}$ succinate, $0.5 \mu \mathrm{M}$ rotenone and mitochondria (adjusted to a protein concentration of $0.4 \mathrm{~g}$ protein/l) were added. Then, calcium chloride $\left(\mathrm{CaCl}_{2}\right)$ was added at the amounts described in the figure captions at an interval of 75 or $150 \mathrm{~s}$. The probe reversibly binds to calcium ions. After each calcium addition, the fluorescence of the probe increased, and then it decreased when the added calcium had accumulated. When the accumulated calcium reached the critical intramitochondrial concentration required for 
pore opening, it was released, and the fluorescence rose dramatically (Ichas et al. 1997, Fontaine et al. 1998a).

\section{Statistical analysis}

The experiments were performed at least five times; representative results are shown. Values are depicted as the means $\pm \mathrm{SD} ; \mathrm{p}<0.05$ was set as the threshold for statistical significance. Statistical evaluation was performed using GraphPad Prism 6.01 software (La Jolla, CA, USA). The data were first tested for normality by means of the Kolmogorov-Smirnov test. None of the data followed a Gaussian distribution and thus were all analysed by nonparametric tests. For the evaluation of the effects of different amounts of added calcium during the same interval, we used the Kruskal-Wallis test followed by Dunn's multiple comparisons test. For the comparison of changes between different time intervals and for evaluation of changes in the calcium/protein ratio, an unpaired two-tailed Mann-Whitney test was used.

\section{Results}

In this communication, we claim that CRC values are dependent on the experimental conditions used, namely on the amount of calcium added in various portions required for the pore opening, and on the intervals between calcium additions.

When $1.25,2.5,5$ and $10 \mathrm{nmol} \mathrm{CaCl}_{2}$ were added in $150 \mathrm{~s}$ intervals, the $\mathrm{CRC}$ values increased at $2.5 \mathrm{nmol} \mathrm{Ca}$ by $147.8 \%$, at $5 \mathrm{nmol} \mathrm{Ca}$ by $226 \%$, and at $10 \mathrm{nmol} \mathrm{Ca}$ by $303.5 \%$ compared with those from $1.25 \mathrm{nmol} \mathrm{Ca}$ additions (Fig. 1A, Fig. 2AB, Fig. 3AB).

When different amounts of calcium were added in $75 \mathrm{~s}$ intervals (Fig. 2AB, Fig. 3AB), CRC values were significantly increased to $130-140 \%$ at all $\mathrm{Ca}$ doses (1.25-10 nmol) compared with those from doses added in $150 \mathrm{~s}$ intervals (Table 1).

When the protein concentration in the incubation medium differed, the values of CRC did not change (Fig. 4).
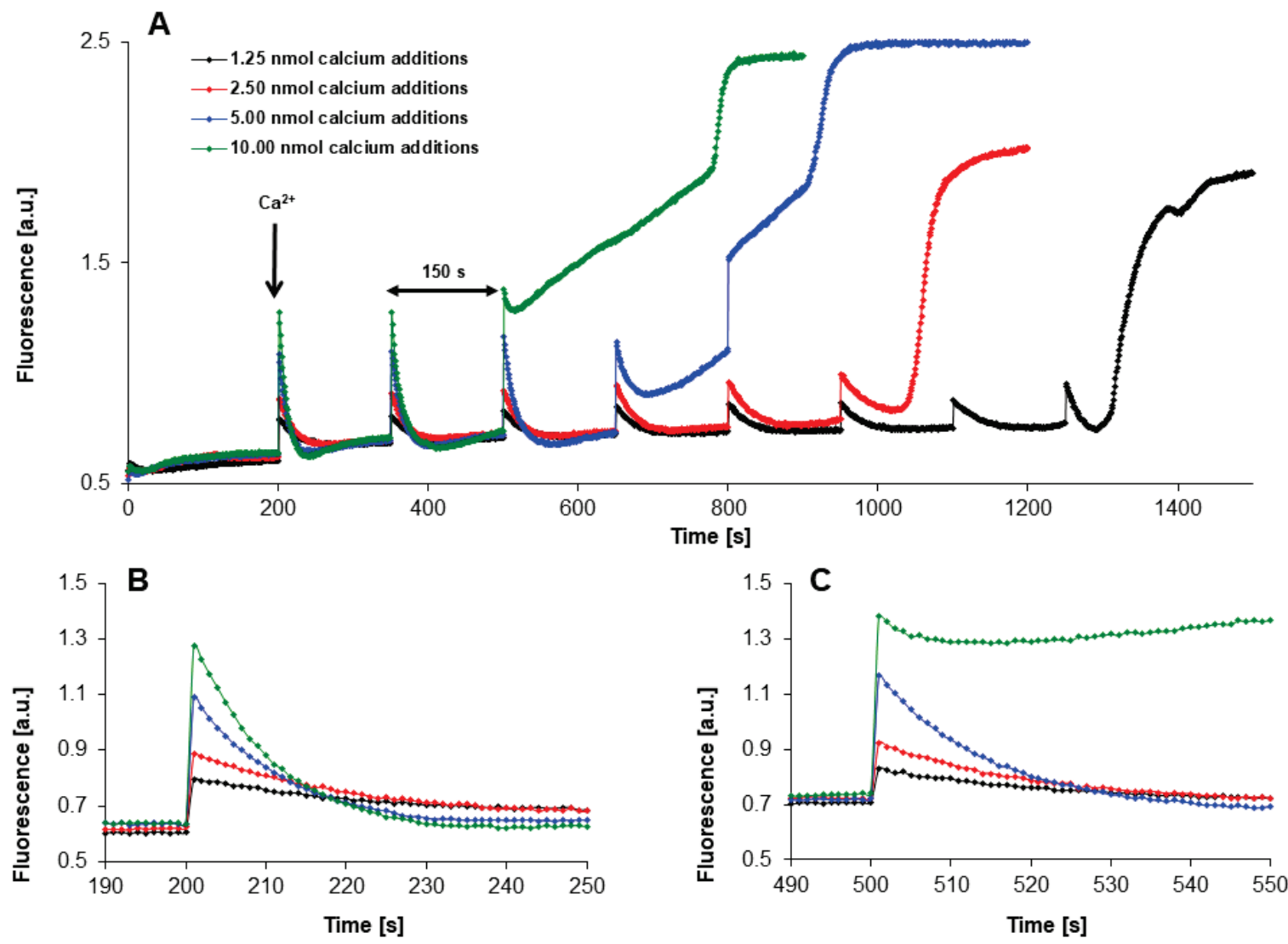

Fig. 1. CRC values depend on the amount of calcium added to induce pore opening. Determination of the CRC of isolated rat liver mitochondria incubated in the medium, as described in the Methods, with different amounts of added calcium. A total of 1.25, 2.5, 5 and $10 \mathrm{nmol}$ of calcium chloride were added to the mitochondrial suspension in $150 \mathrm{~s}$ intervals. Fluorescence data (a.u. arbitrary unit) were registered in $1 \mathrm{~s}$ intervals $(\mathbf{A})$. Evaluation of changes in fluorescence data after the $1^{\text {st }}$ calcium addition at high resolution (B). Evaluation of changes in fluorescence data after the $3^{\text {rd }}$ calcium addition at high resolution (C). 

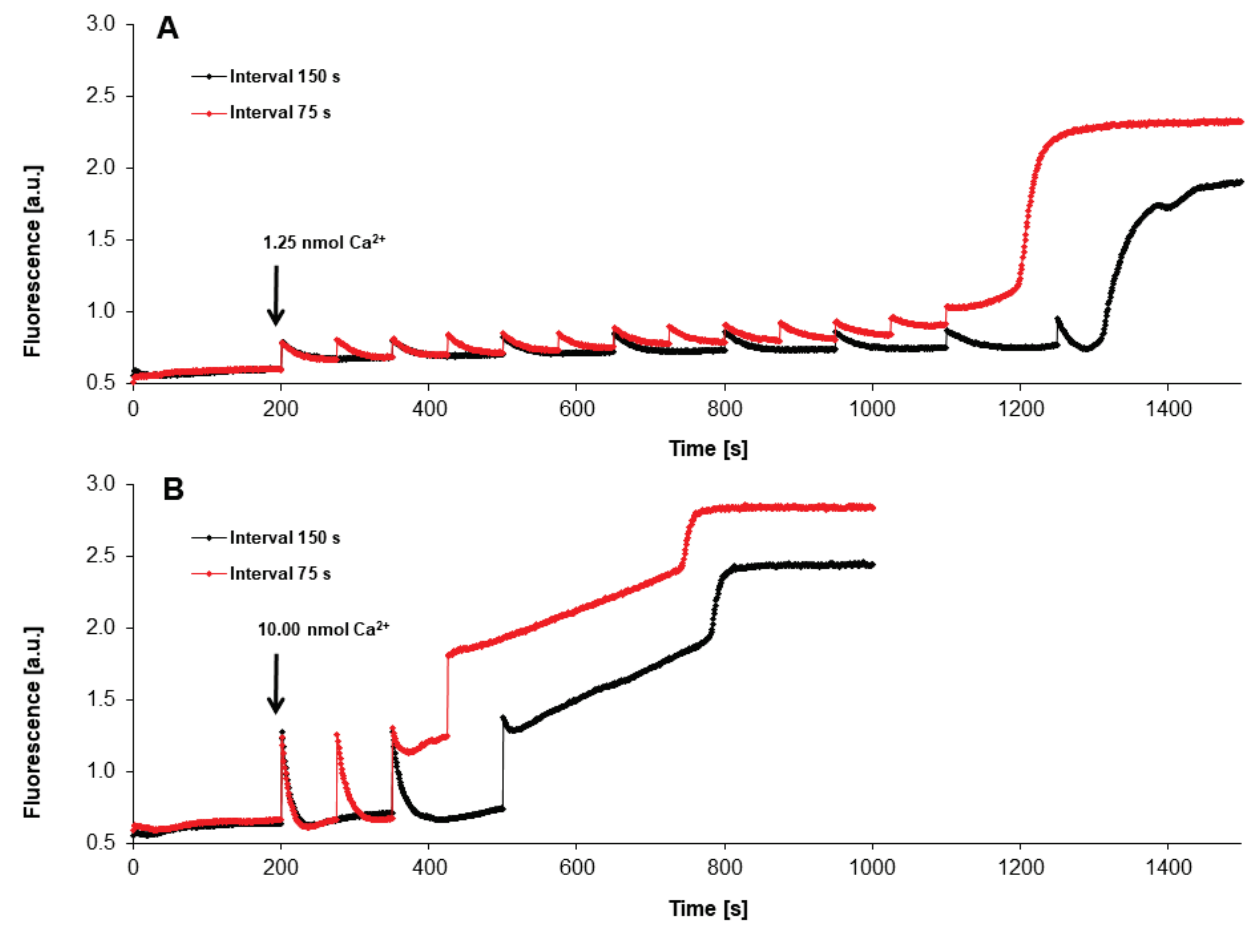

Fig. 2. $C R C$ values depend on the interval between sequential additions of calcium. Determination of the CRC of isolated rat liver mitochondria with the addition of $1.25 \mathrm{nmol}$ calcium chloride at 150 and $75 \mathrm{~s}$ intervals (A) and with the addition of $10 \mathrm{nmol}$ of calcium chloride in 150 and $75 \mathrm{~s}$ intervals (B). Fluorescence data are in arbitrary unit (a.u.).

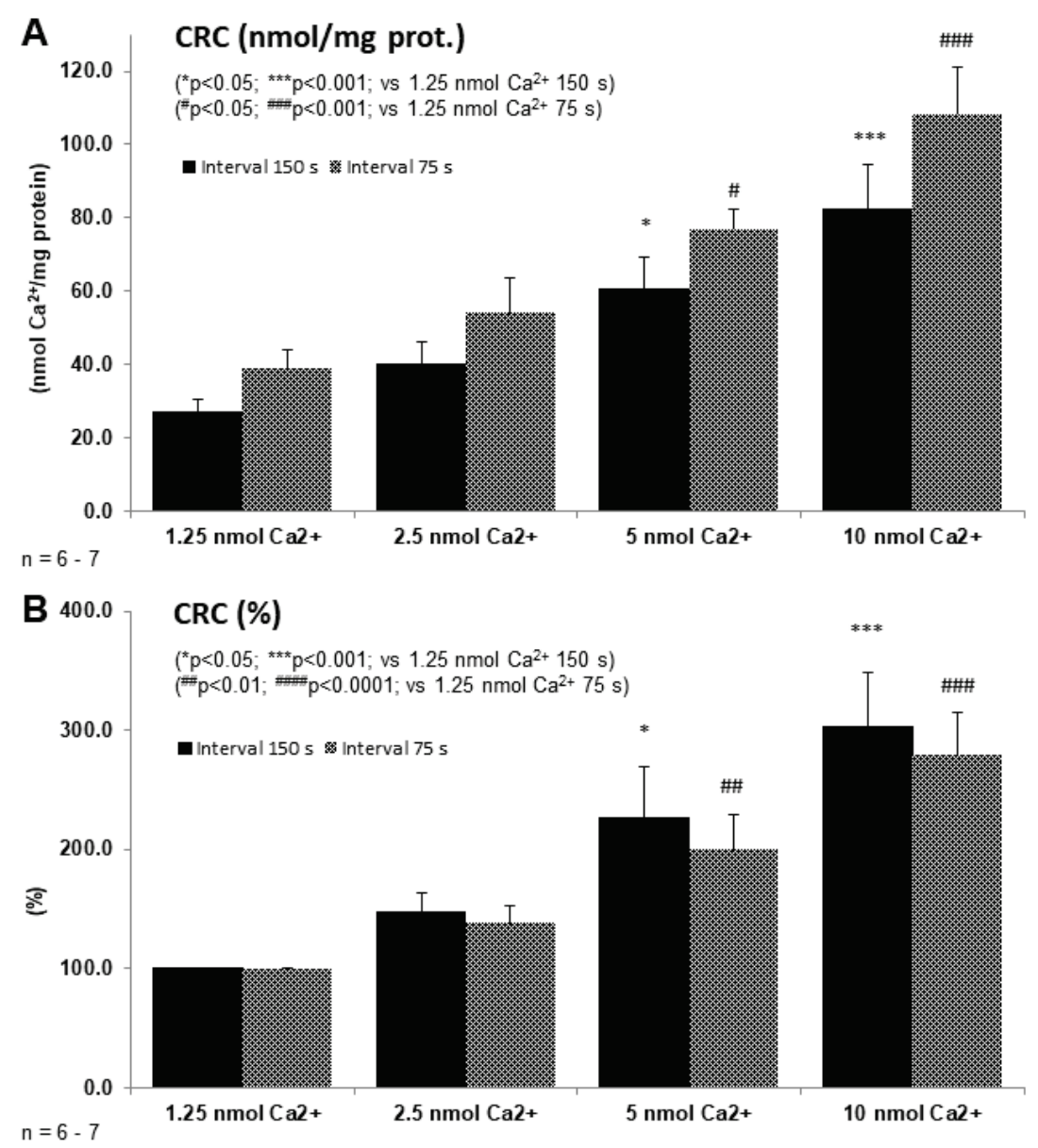

Fig. 3. Statistical evaluation of CRC changes. Statistical evaluation of changes in CRC upon adding different amounts of calcium chloride $(1.25,2.5,5$, and $10 \mathrm{nmol})$ in 150 or $75 \mathrm{~s}$ intervals (A). Statistical evaluation of CRC changes (\%) (B). 


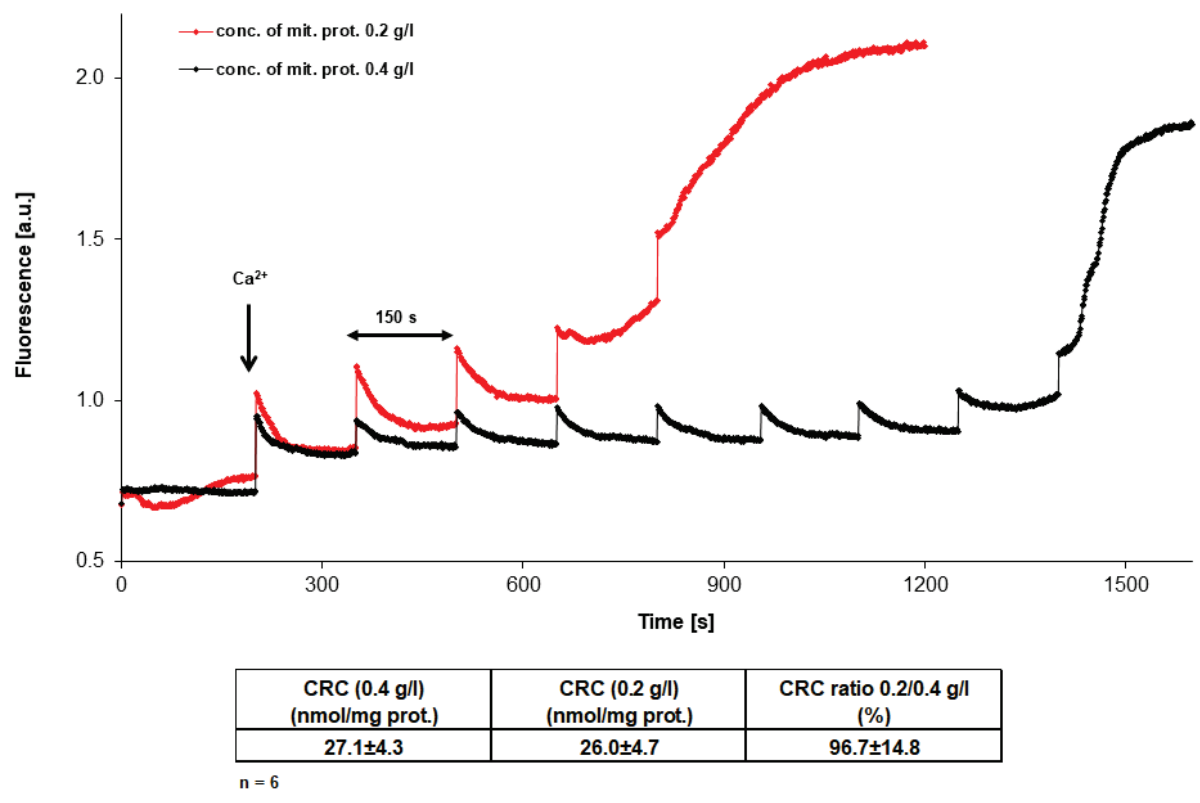

Fig. 4. $C R C$ values in different calcium/protein ratio. Determination of CRC using different calcium/mitochondrial protein ratios. Amount of calcium added to both mitochondrial preparations was equal $(1.25 \mathrm{nmol})$; intervals between calcium additions were also the same (150 s). Fluorescence is expressed in arbitrary unit (a.u.).

Table 1. CRC values determined by adding different amounts of calcium chloride in 150 or $75 \mathrm{~s}$ intervals and statistical evaluation of CRC changes.

\begin{tabular}{lccc}
\hline $\mathbf{C a}^{2+}$ amount per addition & $\begin{array}{c}\text { CRC (150 s interval) } \\
\text { (nmol/mg prot.) }\end{array}$ & $\begin{array}{c}\text { CRC (75 s interval) } \\
\text { (nmol/mg prot.) }\end{array}$ & $\begin{array}{c}\text { CRC ratio 75/150 s intervals } \\
\text { (\%) }\end{array}$ \\
\hline $1.25 \mathrm{nmol} \mathrm{Ca}^{2+}$ & $27.2 \pm 3.5$ & $39.1 \pm 5.1$ & $142.5 \pm 19.6^{* *}$ \\
$2.5 \mathrm{nmol} \mathrm{Ca}^{2+}$ & $40.2 \pm 6.1$ & $54.2 \pm 9.4$ & $134 \pm 19.2^{*}$ \\
$5 \mathrm{nmol} \mathrm{Ca}^{2+}$ & $60.7 \pm 8.6$ & $77.1 \pm 5.1$ & $129.4 \pm 16.0^{* *}$ \\
$10 \mathrm{nmol} \mathrm{Ca}^{2+}$ & $82.1 \pm 12.2$ & $108.3 \pm 12.9$ & $130.6 \pm 4.3^{*}$ \\
\hline
\end{tabular}

$\mathrm{n}=6-7 ; * \mathrm{p}<0.05 ; * * \mathrm{p}<0.01$.

All these data show that the novel method of determining CRC value must be standardized for obtaining reproducible and generally comparable CRC data from different laboratories. This standardization is needed because the CRC values are modified not only by the composition of the incubation medium but also by the experimental protocol used.

We also present data demonstrating that additional information may be acquired from classic CRC curves. When the fluorescence curves from Fig. 1A are evaluated at greater detail, we can see that after the first calcium addition with all calcium amounts used $(1.25-10 \mathrm{nmol})$, the increased fluorescence values obtained after calcium addition return quickly back to the basal values (Fig. 1B). This finding indicates that, after all the added calcium had been accumulated in the mitochondria, the pore remained closed (Fig. 1B). The same picture was obtained after the second calcium addition. However, after the third calcium addition (Fig. 1C), there was a decrease in fluorescence to basal values only after lower amounts of calcium were added (1.25, 2.5 and $5 \mathrm{nmol})$. After the highest amount of $10 \mathrm{nmol}$ was added, there was only a small fluorescence decrease over a short period of time, followed by a period of large increase, which indicates opening of the pore and release of the accumulated calcium from the intramitochondrial space.

Moreover, another interesting detail can be inferred from Fig. 1A. It is obvious that, after the $8^{\text {th }}$ and $6^{\text {th }}$ additions of the two lowest calcium amounts ( 1.25 and $2.5 \mathrm{nmol}$ ), the calcium had accumulated, and the pore remained closed. However, after a short period of time, the pore was completely opened. At the two highest calcium amounts (5 and $10 \mathrm{nmol}$ ), we also observed two 
possible rates of pore opening. This finding suggests that, after those particular additions, some duration of calcium action was required for complete pore opening by the calcium accumulated in mitochondria (Fig. 1A).

To confirm this time-dependent effect of accumulated calcium in further experiments, we present other data indicating that opening of the pore may have transpired over several phases (Fig. 5). For this experiment, we added increasing calcium amounts (5-200 nmol $\left.\mathrm{CaCl}_{2}\right)$ only once, and we followed the fluorescence changes for a longer period of time. At the lowest doses of calcium added (5 and $10 \mathrm{nmol}$ ), we observed a small increase in fluorescence due to the added calcium and a decrease in the fluorescence due to accumulation in the mitochondria. Fluorescence values returned to baseline and remained without change, which indicated that the pore was closed. However, after a long time period ( 900 to $1200 \mathrm{~s}$ ), the fluorescence increased, indicating complete pore opening. These data show that even very low concentrations of accumulated calcium considered ineffective during initial pore opening may be effective after a longer period of action. Our data document that the time period required for pore opening after calcium accumulation in mitochondria was shorter when increased calcium concentrations were added (Fig. 5). Curves obtained after the addition of 15, 25 and $50 \mathrm{nmol}$ of calcium reveal two different pore opening rates. Curves with 100 and $200 \mathrm{nmol}$ of calcium show only a small fluorescence decrease followed by an increase in fluorescence, indicating that the pore had fully opened. This figure also demonstrates that our experiments are performed at the calcium concentration range when Calcium Green is not yet fully saturated by calcium.

As shown in Fig. 5, the MPTP opens by the lowest calcium amount if it can act over a longer period. Additionally, even with higher calcium amounts added, it is obvious that some time passes before the accumulated calcium activates complete pore opening. Therefore, we may conclude that a dose-dependent time period is required before calcium accumulation in the matrix activates complete pore opening. Our data also show that the pore opening may transpire over several phases that are dependent on the amount of calcium in the mitochondrial matrix and on the duration of its action.

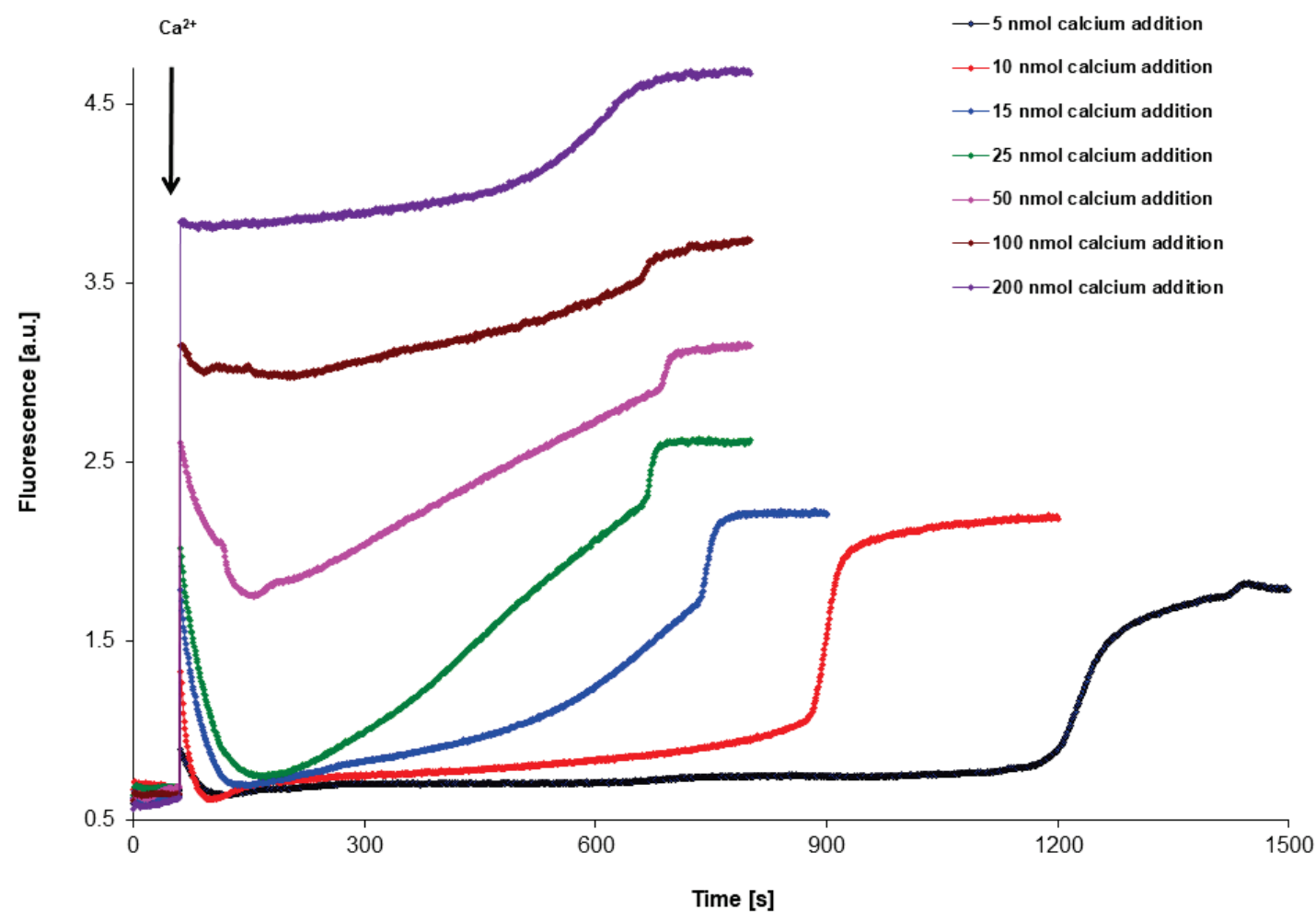

Fig. 5. MPTP opening after adding a single dose of calcium. Determination of fluorescence changes (a.u., arbitrary units) in mitochondrial suspension after adding a single dose of an increasing amount of calcium chloride (5-200 nmol). Experimental conditions are as described in the Methods. 


\section{Discussion}

Data presented in this communication add support to our previous findings indicating that the measurement of CRC values had not been well defined because CRC values depend on more factors than the medium composition used (Endlicher et al. 2019). We have shown in this communication that CRC also depends on the calcium amounts used to trigger MPTP opening and on the intervals between calcium additions but not on the calcium/protein ratio in measured preparations. Therefore, for comparability of CRC values described in the literature, it is necessary to provide and consider the factors mentioned above and standardize reporting the experimental conditions in more detail. Obviously, many other factors remain that might affect CRC measurements. The main problem in studies of the MPTP is that this pore has a very important role in the pathogenesis of many diseases, and although we know much about its function and regulation, our knowledge about its molecular structure is still insufficient.

Therefore, in this communication, we focused on elucidating the factors that can modify the CRC values, and we also showed that more data about the mechanism of the MPTP opening may be acquired from fluorescence curves because the fluorescence method is much more sensitive than the swelling method. We have shown that not only the medium composition but also the experimental protocol used may considerably affect the values of calcium retention capacity (Endlicher et al. 2019). Here, we describe two factors that should be taken into account when data from different laboratories are compared. The first factor described is the amount of calcium added to induce pore opening. Some authors prefer high peaks caused by the adding greater amounts of calcium ions, which open the pore more quickly (Fontaine et al. 1998b). Some prefer low peaks caused by lower amounts of calcium, which take more time to reach complete pore opening (Pardo et al. 2015). The next important factor that must be controlled for is the interval between sequential additions of calcium. We observed that changes in both above-mentioned parameters resulted in very different CRC values. Therefore, it is important to obtain consensus on the experimental protocol for the measurement of CRC values.

However, even more important is the fact that 67 years after MPTP discovery, we still do not know its molecular structure. Discussions regarding whether MPTP is a pore or just an unspecific hole in the mitochondrial membrane continue (Szabo and Zoratti 2014). The titles of many recent reviews point out words such as "Fixing a hole" (Di Lisa and Bernardi 2006), "MPTP: a mystery solved?" (Bernardi 2013), "MPTP: Where the known meets unknown" (Juhaszova et al. 2008), and "Enjoy the trip: Calcium in Mitochondria Back and Forth" (De Stefani et al. 2016).

These reviews demonstrate almost 50 years of unsuccessful work to resolve the problem of the molecular structure of the MPTP. Certainly new strategies and new methods are required. However, before new ideas and methods are accessible, there is still a chance to address remaining problems related to pore function, regulation and specificity, as well as its involvement in multiple pathologies, e.g. cardiovascular diseases (Weiss et al. 2003), cancer (Biasutto et al. 2010, Bonora and Pinton 2014), neurodegenerative diseases (Rao et al. 2014, Nicholls 2017), diabetes mellitus (Skrha et al. 2011), and liver steatosis (Einer et al. 2018), by the two methods available. These data will be important for both diagnosis and treatment.

\section{Conflict of Interest}

There is no conflict of interest.

\section{Acknowledgements}

This work was supported by the Charles University Program PROGRES Q40/02 and the Ministry of Education, Youth and Sports Project InterCost LTC17044. Language of this manuscript was corrected by the American Journal Experts, certificate verification key: D826-8D49-62EB-D714-E756.

\section{References}

ALAVIAN KN, BEUTNER G, LAZROVE E, SACCHETTI S, PARK HA, LICZNERSKI P, LI H, NABILI P, HOCKENSMITH K, GRAHAM M, PORTER GA JR, JONAS EA: An uncoupling channel within the csubunit ring of the F1FO ATP synthase is the mitochondrial permeability transition pore. Proc Natl Acad Sci U S A 111: 10580-10585, 2014. https://doi.org/10.1073/pnas.1401591111 
BERNARDI P: The mitochondrial permeability transition pore: a mystery solved? Front Physiol 4: 95, 2013. https://doi.org/10.3389/fphys.2013.00095

BIASUTTO L, AZZOLINI M, SZABO I, ZORATTI M: The mitochondrial permeability transition pore in AD 2016: An update. Biochim Biophys Acta 1863: 2515-2530, 2016. https://doi.org/10.1016/j.bbamcr.2016.02.012

BIASUTTO L, DONG LF, ZORATTI M, NEUZIL J: Mitochondrially targeted anti-cancer agents. Mitochondrion 10: 670-681, 2010. https://doi.org/10.1016/j.mito.2010.06.004

BONORA M, PINTON P: The mitochondrial permeability transition pore and cancer: molecular mechanisms involved in cell death. Front Oncol 4: 302, 2014. https://doi.org/10.3389/fonc.2014.00302

BRADFORD MM: A rapid and sensitive method for the quantitation of microgram quantities of protein utilizing the principle of protein-dye binding. Anal Biochem 72: 248-254, 1976. https://doi.org/10.1016/00032697(76)90527-3

BUSTAMANTE E, SOPER JW, PEDERSEN PL: A high-yield preparative method for isolation of rat liver mitochondria. Anal Biochem 80: 401-408, 1977. https://doi.org/10.1016/0003-2697(77)90661-3

CARAFOLI E, SANTELLA L, BRANCA D, BRINI M: Generation, control, and processing of cellular calcium signals. Crit Rev Biochem Mol Biol 36: 107-260, 2001. https://doi.org/10.1080/20014091074183

DE STEFANI D, RIZZUTO R, POZZAN T: Enjoy the trip: calcium in mitochondria back and forth. Annu Rev Biochem 85: 161-192, 2016. https://doi.org/10.1146/annurev-biochem-060614-034216

DI LISA F, BERNARDI P: Mitochondria and ischemia-reperfusion injury of the heart: fixing a hole. Cardiovasc Res 70: 191-199, 2006. https://doi.org/10.1016/j.cardiores.2006.01.016

DRAHOTA Z, ENDLICHER R, STANKOVA P, RYCHTRMOC D, MILEROVA M, CERVINKOVA Z: Characterization of calcium, phosphate and peroxide interactions in activation of mitochondrial swelling using derivative of the swelling curves. J Bioenerg Biomembr 44: 309-315, 2012a. https://doi.org/10.1007/s10863$\underline{012-9443-2}$

DRAHOTA Z, MILEROVÁ M, ENDLICHER R, RYCHTRMOC D, ČERVINKOVÁ Z, OŠŤÁDAL B: Developmental changes of the sensitivity of cardiac and liver mitochondrial permeability transition pore to calcium load and oxidative stress. Physiol Res 61 (Suppl 1): S165-S172, 2012 b.

EINER C, HOHENESTER S, WIMMER R, WOTTKE L, ARTMANN R, SCHULZ S, GOSMANN C, SIMMONS A, LEITZINGER C, EBERHAGEN C, BORCHARD S, SCHMITT S, HAUCK SM, VON TOERNE C, JASTROCH M, WALHEIM E, RUST C, GERBES AL, POPPER B, MAYR D, SCHNURR M, VOLLMAR AM, DENK G, ZISCHKA H: Mitochondrial adaptation in steatotic mice. Mitochondrion 40: 1-12, 2018. https://doi.org/10.1016/j.mito.2017.08.015

ENDLICHER R, DRAHOTA Z, CERVINKOVA Z: Modification of calcium retention capacity of rat liver mitochondria by phosphate and tert-butyl hydroperoxide. Physiol Res 68: 59-65, 2019. https://doi.org/10.33549/physiolres.933912

ENDLICHER R, KRIVAKOVA P, LOTKOVA H, MILEROVA M, DRAHOTA Z, CERVINKOVA Z: Tissue specific sensitivity of mitochondrial permeability transition pore to $\mathrm{Ca} 2+$ ions. Acta Medica (Hradec Kralove) 52: 69-72, 2009. https://doi.org/10.14712/18059694.2016.107

FONTAINE E, ERIKSSON O, ICHAS F, BERNARDI P: Regulation of the permeability transition pore in skeletal muscle mitochondria. Modulation By electron flow through the respiratory chain complex I. J Biol Chem 273: 12662-12668, 1998a. https://doi.org/10.1074/jbc.273.20.12662

FONTAINE E, ICHAS F, BERNARDI P: A ubiquinone-binding site regulates the mitochondrial permeability transition pore. J Biol Chem 273: 25734-25740, 1998b. https://doi.org/10.1074/jbc.273.40.25734

HALESTRAP AP: What is the mitochondrial permeability transition pore? J Mol Cell Cardiol 46: 821-831, 2009. https://doi.org/10.1016/j.yjmcc.2009.02.021

HALESTRAP AP, CONNERN CP, GRIFFITHS EJ, KERR PM: Cyclosporin A binding to mitochondrial cyclophilin inhibits the permeability transition pore and protects hearts from ischaemia/reperfusion injury. Mol Cell Biochem 174: 167-172, 1997. https://doi.org/10.1007/978-1-4615-6111-8_25

HE J, FORD HC, CARROLL J, DING S, FEARNLEY IM, WALKER JE: Persistence of the mitochondrial permeability transition in the absence of subunit $\mathrm{c}$ of human ATP synthase. Proc Natl Acad Sci U S A 114: 3409-3414, 2017. https://doi.org/10.1073/pnas.1702357114 
ICHAS F, JOUAVILLE LS, MAZAT JP: Mitochondria are excitable organelles capable of generating and conveying electrical and calcium signals. Cell 89: 1145-1153, 1997. https://doi.org/10.1016/s0092-8674(00)80301-3

JUHASZOVA M, WANG S, ZOROV DB, NUSS HB, GLEICHMANN M, MATTSON MP, SOLLOTT SJ: The identity and regulation of the mitochondrial permeability transition pore: where the known meets the unknown. Ann N Y Acad Sci 1123: 197-212, 2008. https://doi.org/10.1196/annals.1420.023

MILEROVÁ M, DRAHOTA Z, CHYTILOVÁ A, TAUCHMANNOVÁ K, HOUŠTĚK J, OŠŤÁDAL B: Sex difference in the sensitivity of cardiac mitochondrial permeability transition pore to calcium load. Mol Cell Biochem 412: 147-154, 2016. https://doi.org/10.1007/s11010-015-2619-4

NICHOLLS DG: Brain mitochondrial calcium transport: Origins of the set-point concept and its application to physiology and pathology. Neurochem Int 109: 5-12, 2017. https://doi.org/10.1016/j.neuint.2016.12.018

PANOV A, DIKALOV S, SHALBUYEVA N, HEMENDINGER R, GREENAMYRE JT, ROSENFELD J: Speciesand tissue-specific relationships between mitochondrial permeability transition and generation of ROS in brain and liver mitochondria of rats and mice. Am J Physiol Cell Physiol 292: C708-C718, 2007. https://doi.org/10.1152/ajpcell.00202.2006

PARDO AC, RINALDI GJ, MOSCA SM: Mitochondrial calcium handling in normotensive and spontaneously hypertensive rats: correlation with systolic blood pressure levels. Mitochondrion 20: 75-81, 2015. https://doi.org/10.1016/j.mito.2014.12.003

RAAFLAUB J: Die schwellung isolierter leberzellmitochondrien und ihre physikalisch-chemische beeinflussbarkeit. Helv Physiol Pharmacol Acta 11: 142-156, 1953.

RAO VK, CARLSON EA, YAN SS: Mitochondrial permeability transition pore is a potential drug target for neurodegeneration. Biochim Biophys Acta 1842: 1267-1272, 2014. https://doi.org/10.1016/j.bbadis.2013.09.003

SKRHA J JR, GALL J, BUCHAL R, SEDLACKOVA E, PLATENIK J: Glucose and its metabolites have distinct effects on the calcium-induced mitochondrial permeability transition. Folia Biol (Praha) 57: 96-103, 2011.

SMITH RAJ, HARTLEY RC, COCHEME HM, MURPHY MP: Mitochondrial pharmacology. Trends Pharmacol Sci 33: 341-352, 2012. https://doi.org/10.1016/j.tips.2012.03.010

SZABO I, ZORATTI M: Mitochondrial channels: ion fluxes and more. Physiol Rev 94: 519-608, 2014. https://doi.org/10.1152/physrev.00021.2013

WEISS JN, KORGE P, HONDA HM, PING P: Role of the mitochondrial permeability transition in myocardial disease. Circ Res 93: 292-301, 2003. https://doi.org/10.1161/01.RES.0000087542.26971.D4 